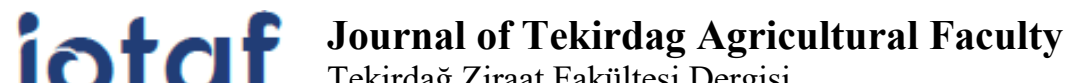

Tekirdağ Ziraat Fakültesi Dergisi

\section{Çukurova Yöresi Koşullarında Bazı Buharlaşma Modellerinin Performanslarının Değerlendirilmesi}

\author{
Assessment of the Performance of Some Evaporation Models Under Çukurova Region \\ Conditions
}

\section{Deniz Levent KOÇ}

\section{$\ddot{O} z$}

Buharlaşma, su döngüsünün anahtar bileşenidir. Buharlaşma miktarının belirlenmesinin; su kaynaklarının yönetimi, su varlığının belirlenmesi, sulama programlaması ve çevresel modelleme çalışmalarında çok önemli bir yeri vardır. A sınıfı buharlaşma kapları açık su yüzeyi buharlaşmasını ölçmek, tarla-bahçe bitkilerinin sulama programlaması ve su yönetimi için; bitki su tüketimlerini tahmin etmek amacıyla tüm dünyada yaygın olarak kullanılmaktadır. Pratik, teorik veya finansal nedenlerden dolayı kap buharlaşmasını ölçmek her zaman mümkün olmayabilir. Açık su yüzeyi buharlaşmasını meteorolojik verilerden kestirmek için pek çok model geliştirilmiştir. $\mathrm{Bu}$ çalışmada, bunlardan sıcaklığa, radyasyona, kütle transferine ve kombinasyona dayalı olan toplam 10 buharlaşma modeli (Penman-1948, Kohler-Nordenson-Fox (KNF)-1955, Papadakis-1961, Hamon-1961, Antal1973, Linacre-1977, Hanson\&Rauzi-1977, Kharrufa-1985, Abtew-1996, Modified-Turc-1996) Çukurova yöresi bitki büyüme mevsimi boyunca, 30 yıllık iklim verisi kullanılarak A sınıfı buharlaşma kaplarında günlük olarak ölçülen buharlaşma değerlerini kestirmek için kullanılmıştır. Modellerin doğruluğunun ve güvenirliliğinin belirlenmesinde ortalama karekök hatası (RMSE), ortalama sapma hatası (MBE) ve bağıl hata (RE) istatistiksel yaklaşımlarından yararlanılmıştır. Araşıırmadan elde edilen sonuçlara göre; Çukurova yöresi koşullarında A sınıfı buharlaşma kaplarından oluşan buharlaşmayı kestirmede en başarılı model, en düşük mevsimsel ortalama RMSE, RE ve MBE değerleriyle KNF (RMSE $=1.5 \mathrm{~mm} \mathrm{gün}^{-1}, \mathrm{RE}=0.4, \mathrm{MBE}=-0.1 \mathrm{~mm}$ gün ${ }^{-1}$ ) olurken; en yüksek RMSE, RE ve MBE değerleriyle Hamon ( $R M S E=6.9 \mathrm{~mm}$ gün $^{-1}, \mathrm{RE}=1.3 \mathrm{MBE}=6 \mathrm{~mm}$ gün ${ }^{-1}$ ) en başarısız model olmuştur. Araştırmada, Hanson \& Rauzi modelide KNF modeline oldukça yakın sonuçlar vermiştir (mevsimsel ortalama değerler: RMSE $=1.6 \mathrm{~mm}$ gün $^{-1}, \mathrm{RE}=0.4 \mathrm{MBE}=0.7 \mathrm{~mm}_{\text {gün }}{ }^{-1}$ ). Ayrıca, Hanson \& Rauzi modelinin $\mathrm{KNF}$ modeline göre daha az meteorolojik veri kullanması, Hanson \& Rauzi modelinin Çukurova yöresi koşullarında KNF'ye alternatif olabileceğini göstermiştir.

Anahtar Kelimeler: Buharlaşma, Buharlaşma modelleri, A sınıfı buharlaşma kabı, Çukurova yöresi, Performans

\footnotetext{
1*Sorumlu Yazar/Corresponding Author: Deniz Levent KOÇ, Çukurova Üniversitesi, Ziraat Fakültesi, Tarımsal Yapılar ve Sulama Bölümü, Adana, Türkiye E-mail: leventk@cu.edu.tr (iD OrcID: 0000-0002-4495-3060

Atıf/Citation: Deniz Levent KOÇ, Çukurova Yöresi Koşullarında Bazı Buharlaşma Modellerinin Performanslarının Değerlendirilmesi. Tekirdağ Ziraat Fakültesi Dergisi, 19 (1), 145-155

CBu çalışma Tekirdağ Namık Kemal Üniversitesi tarafından Creative Commons Lisansı (https://creativecommons.org/licenses/by-nc/4.0/) kapsamında yayınlanmıştır. Tekirdağ 2022 


\begin{abstract}
Evaporation is the main factor of the water cycle. The quantification of evaporation is crucial for water resource management, determination of water availability, irrigation scheduling, and environmental modeling studies. Class A pans are commonly used worldwide to measure evaporation from open water surface and to estimate evapotranspiration for irrigation scheduling and water management for field and horticultural crops. Continuous measurement of daily pan evaporation may not be possible due to practical, theoretical, or financial reasons. Many models have been developed to estimate evaporation from open water surface using meteorological data. In this study, a total of 10 evaporation models based on temperature, radiation, mass transfer, and combination (Penman1948, Kohler-Nordenson-Fox (KNF)-1955, Papadakis-1961, Hamon-1961, Antal-1973, Linacre-1977, Hanson \& Rauzi-1977, Kharrufa-1985, Abtew-1996, Modified-Turc-1996) were used to estimate daily measured evaporation values in Class A pan using 30-year climate data for the summer growing season in the Çukurova region. Root mean square error (RMSE), mean bias error (MBE), and relative error (RE) statistic approaches were used to determine the accuracy and reliability of the models. According to results obtained from the research, the KNF model was the best model with the seasonal mean lowest RMSE, RE, and MBE values $\left(\mathrm{RMSE}=1.5 \mathrm{~mm}^{\mathrm{day}}{ }^{-1}\right.$, $\left.\mathrm{RE}=0.4, \mathrm{MBE}=-0.1 \mathrm{~mm} \mathrm{day}^{-1}\right)$, whereas Hamon was the worst model with the seasonal mean highest RMSE, $\mathrm{RE}$, and $\mathrm{MBE}$ values $\left(\mathrm{RMSE}=6.9 \mathrm{~mm} \mathrm{day}^{-1}, \mathrm{RE}=1.3, \mathrm{MBE}=6 \mathrm{~mm} \mathrm{day}^{-1}\right)$ to estimate evaporation from Class A Pan. In the study, the Hanson \& Rauzi model gave very similar results to the KNF model (seasonal mean values: $\left.\mathrm{RMSE}=1.6 \mathrm{~mm}_{\text {day }}{ }^{-1}, \mathrm{RE}=0.4, \mathrm{MBE}=0.7 \mathrm{~mm} \mathrm{day}^{-1}\right)$. In addition, the fact that the Hanson \& Rauzi model uses less meteorological data than the KNF model has shown that the Hanson \& Rauzi model can be an alternative to the KNF model under the conditions of the Çukurova region.
\end{abstract}

Keywords: Evaporation, Evaporation models, Class A pan, Çukurova region, Performance 


\section{Giriş}

Buharlaşma olayı; sıvı halde bulunan suyun, su buharına dönüştüğü anda meydana gelmektedir. Buharlaşma hızı, su yüzeyinde enerjinin mevcut olması ve su buharının atmosfere karışabilme olanağı ile denetlenir. Su kütlesi tarafından tutulan radyant enerji (net radyasyon) yıllık buharlaşma miktarını etkileyen en önemli parametredir. Buharlaşma; solar radyasyon, sıcaklık, rüzgâr hızı, buhar basıncı açığı, atmosfer basıncı ve çevresel ortamın bir fonksiyonudur (Abtew, 2001).

Literatürde, açık su yüzeyi buharlaşmasını kestirmek için çok sayıda yöntem rapor edilmiştir. Bunlar; kap buharlaşması ( $\left.\mathrm{E}_{\mathrm{pan}}\right)$ yöntemi, kütle dengesi yöntemi, enerji bütçesi modelleri, yı̆̆ın transfer modelleri, kombinasyon modelleri ve denge-sıcaklık yöntemi olarak sinıflandırılabilir (Winter ve ark., 1995). Her metedolojinin uygulama alanı ve sınırlamaları vardır. Örneğin, Eddy korelasyon yöntemi, göl buharlaşmasının belirlenmesine yönelik doğrudan bir yöntem olarak kabul edilir ancak, maliyet sınırlamaları nedeniyle yaygın olarak kullanılmaz. Kütle transfer yöntemi, büyük derin göllerde yaygın olarak kullanılmaktadır. Kombinasyon yöntemleri hem göle enerji girdisini hem de kütle transferi kavramını dikkate alır ancak çok fazla veri gerektiren bir yöntemdir. A sınıfı buharlaşma kapları (Class A Pan) göllerden olan buharlaşmanın belirlenmesinde kullanılan en yaygin yöntemdir (Finch ve Hall, 2001).

A sınıfı buharlaşma kapları, serbest su yüzeyi buharlaşmasını ölçerek; bitkilerin sulama planlamasının ve su yönetiminin yapılabilmesi için, kıyas bitki su tüketimini $\left(\mathrm{ET}_{0}\right)$ tahmin etmek amacıyla kullanılmaktadır. Ayrıca kap yöntemi; yaban hayatı ve ekolojik habitatın yönetimi için göllerden, sulak alanlardan, nehirlerden, rezervuarlardan ve diğer su kaynaklarından meydan gelen buharlaşma miktarlarını kestirmek için de yaygın bir şekilde kullanılmaktadır. Bugüne değin birçok araştırmacı tarafindan buharlaşma kaplarının sulama programlarının oluşturulmasında güvenle kullanılabileceğini gösteren çok sayıda çalışma yapılmıştır (Abtew, 2001; Ertek ve ark., 2007; Göçmen ve Erdem, 2019; Yenigün ve Erdem, 2019). E Ean yöntemi, eğer farklı iklim bölgeleri için kalibre edilirse oldukça doğru sonuçlar vermektedir. Çalışmalar, pan katsayılarının doğru bir şekilde belirlenmesi durumunda, $\mathrm{E}_{\text {pan }}$ yönteminin kıyas bitki su tüketiminin $\left(\mathrm{ET}_{0}\right)$ kestiriminde çok güvenilir sonuçlar verdiğini göstermiştir (Irmak ve Haman, 2003; Jensen ve ark., 1990). Bugüne kadar, farklı iklim ve bölgelerde buharlaşma modelleri kullanılarak göllerden, nehirlerden, rezervuarlardan ve A sınıfı buharlaşma kaplarından meydana gelen buharlaşmayı tahmin etmek için çok sayıda çalışma yapılmıştır (Abtew, 2001; Friedrich ve ark., 2018; Irmak ve Haman, 2003; Rosenberry ve ark., 2007).

Abtew (2001)'de Güney Florida'da Okeechobee Gölünde meydana gelen buharlaşmayı tahmin etmek için 5 yıllık iklim verisi ve $\mathrm{E}_{\text {pan }}$ yöntemi, enerji bütçesi, kütle ve momentum transfer yöntemleri ile su bütçesi yaklaşımını kullanmıştır. Çalışmada, Abtew (1996) tarafından geliştirilen basit Abtew modeli ile yine aynı araştırmacı tarafından modifiye edilmiş Turc modeli (Abtew, 1996) A sınıfı kap buharlaşmasını kestirmede en doğru sonucu vermiştir.

Rodrigues ve ark., (2020), Avrupa'nın en büyük yapay göllerinden biri olan Alqueva rezervuarında $E_{\text {pan }}$ ve Eddy kovaryans yöntemleri ile belirlenen buharlaşma değerleri arasında $\mathrm{R}^{2}$ değeri 0.7 olan bir korelasyon bulmuşlardır. Xu ve Singh (2000), İsviçre'deki Changing istasyonundan elde ettikleri iklim verileri ile radyasyona dayal1 5 buharlaşma modelini (Abtew, Hargreaves, Makkink, Priestley \& Taylor ve Turc) Epan yöntemi ile elde edilen buharlaşmayı kestirmek için kullanmışlardır. Çalışmada, Basit Abtew modeli, kap buharlaşmasına en yakın değerleri vermiştir. Diğer 4 modelde ise büyük hatalar ortaya çıkmıştır. Bu 4 yöntem özellikle soğuk aylarda daha düşük değerler kestirmiştir. Bu modeller yeniden kalibre edildiğinde, diğer 3 modelde ortalama yıllık buharlaşma değerlerini doğru bir şekilde kestirmiştir. Araştırmacılar, kalibre edildikten sonra Makkink ve Priestley \& Taylor modellerini çalışma bölgesi için önermişlerdir.

Xu ve Singh (2001), yaptıkları bir diğer çalışmada Ontario (Kanada)'nun kuzey-batı kesiminde bulunan 2 iklim istasyonundan elde ettikleri verilerle 7 sicaklığa dayalı buharlaşma modelinini (Thornthwaite, Linacre, Hargreaves, Kharrufa, Hamon, Romanenko, Blaney-Criddle) A sınıfı kap buharlaşmasını tahmin etmek için kullanmışlardır. Araştırmacılar, modifiye edilmiş olan Blaney_Criddle, Hargreaves ve Thornthwaite modellerini araştırma bölgesi için önermişlerdir.

Irmak ve Haman (2003)'ın, Florida'da A sınıfı kap buharlaşmasını tahmin etmek için 23 yıllık günlük iklim verilerini ve 5 farklı buharlaşma modelini (Penman, KNF, Christiansen, Priestley Taylor ve Linacre) kullandıkları 
Çukurova Yöresi Koşullarında Bazı Buharlaşma Modellerinin Performanslarının çalışmalarında; KNF modelinin, ölçülen $\mathrm{E}_{\text {pan }}$ değerlerine en yakın tahmini yaptığını $\left(\mathrm{RMSE}=0.37 \mathrm{~mm} \mathrm{gün}^{-1}\right.$ ); Linacre modelinin ise $\left(\mathrm{RMSE}=1.33 \mathrm{~mm} \mathrm{gün}^{-1}\right)$ en başarısız tahmin yapan model olduğunu belirtmiş̧lerdir.

Sezer ve Öztekin (2016), 2 yıllık iklim verisi, 2 buharlaşma modeli (Penman, Linacre) ve A sınıfı buharlaşma kabı kullanarak Samsun'da yaptıkları çalışmada, Penman (1948) modelinin $E_{\text {pan }}$ değerlerine daha yakın sonuç verdiğini belirlemişlerdir $\left(\mathrm{R}^{2}=0.52-0.70 ; \mathrm{RMSE}=0.97-1.32 \mathrm{~mm}\right.$ gün $\left.{ }^{-1}\right)$. Aydın (2019), Siirt'te yaptığı bir çalışmada; 2 yıllık iklim verisi ve 2 buharlaşma modeli (Penman, KNF) kullanarak tahmin ettiği buharlaşma değerlerini, A sınıfı buharlaşma kabından elde edilen değerlerle karşılaştırmıştır. Araştırmacı, Penman (1948) modelinin yöre koşullarında daha güvenilir sonuçlar verdiğini rapor etmiştir $\left(\mathrm{R}^{2}=0.80-0.87\right.$; $\mathrm{RMSE}=1.32-1.35$ mm gün $\left.{ }^{-1}\right)$.

Yukarıdaki çalışmalardan da anlaşılacağı gibi, buharlaşma modellerinin doğruluğu bölge, iklim, çevre koşulları ve modellerin kullandıkları iklim parametrelerine bağlı olarak değişmektedir. Kap buharlaşmasının ( $\left.E_{p a n}\right)$ tahmininde, ilgili çevre koşulları için güvenilir bir yöntemin belirlenmesi; bitki büyümesi, hidrolojik ve ekolojik

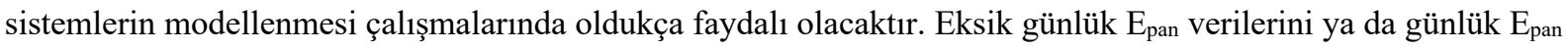
verilerini meteorolojik veriler kullanarak tahmin etmek için, her ilgili bölge ve çevre koşuluna göre güvenilir bir yöntemin belirlenmesine ihtiyaç vardır. Ayrıca, iklimin uzay ve zaman ile değişkenliği nedeniyle, deneysel bir denklemin farklı her iklim koşulunda $\mathrm{E}_{\mathrm{pan}}$ '1 tahmin etmede iyi performans göstermesi beklenmemektedir (Irmak ve Haman, 2003). Bu nedenle, kap buharlaşması modellerinin farklı iklim ve çevre koşulları için değerlendirilmesi gerekir. Bu çalışmada Çukurova koşullarında günlük $\mathrm{E}_{\mathrm{pan}}$ verilerini tahmin etmek için 10 buharlaşma modeli kullanılmış ve modellerin doğruluğu bazı istatistiksel yaklaşımlarla test edilmiştir.

\section{Materyal ve Metot}

\subsection{Araşttrma yeri}

Çalışma Adana yöresinde yapılmıştır. Yörede Akdeniz ikliminin özellikleri egemendir. Uzun yıllık (1990-2019) iklim verilerine göre; ortalama yıllık toplam yağış $653.3 \mathrm{~mm}$ olup; bunun yaklaşık \% 50 'si aralık ve şubat ayları arasında gerçekleşmektedir. Günlük ortalama oransal nem, kış aylarında \% 65.8, yaz aylarında \% 68.9 ve yıllık ortalama olarak \% 66.0'dır. Günlük ortalama rüzgâr hızı, kış aylarında $1.3 \mathrm{~m} \mathrm{~s}^{-1}$ iken yaz aylarında $1.4 \mathrm{~m} \mathrm{~s}^{-1}$; yıllık ortalama olarak ise $1.3 \mathrm{~m} \mathrm{~s}^{-1}$ dir. Günlük ortalama sıcaklık ise; kış aylarında $10.4{ }^{\circ} \mathrm{C}$, yaz aylarında $27.9^{\circ} \mathrm{C}$ ve yıllık ortalama olarak $19.4{ }^{\circ} \mathrm{C}$ 'dir. Çalışmada, uzun yıllık (1990-2019) bazı iklim verilerinin aylık ortalama değerleri Tablo 1'de verilmiştir. Anılan veriler, Adana merkezde bulunan Meteoroloji 6. Bölge Müdürlüğü iklim istasyonundan (enlem $37^{\circ}$ 00' 14", boylam 35²0' 39") sağlanmıştır (Anonim, 2020).

Tablo 1. Araştırma yöresindeki aylık ortalama uzun yıllık iklim verileri (1990-2019)

Table 1. Mean monthly long-term climate data in the research area (1990-2019)

\begin{tabular}{|c|c|c|c|c|c|c|}
\hline & Ocak & Şubat & Mart & Nisan & Mayıs & Haziran \\
\hline $\mathrm{T}_{\max },{ }^{\circ} \mathrm{C}$ & 15.0 & 16.6 & 19.9 & 24.1 & 28.5 & 31.8 \\
\hline $\mathbf{T}_{\min },{ }^{\circ} \mathrm{C}$ & 5.5 & 6.3 & 8.8 & 12.4 & 16.5 & 20.8 \\
\hline $\mathbf{N}$, saat & 4.6 & 5.2 & 6.1 & 7.1 & 8.8 & 10.2 \\
\hline RH, \% & 65.6 & 64.9 & 65.5 & 66.7 & 66.7 & 67.1 \\
\hline $\mathbf{U}, \mathbf{m ~ s}^{-1}$ & 1.3 & 1.4 & 1.4 & 1.4 & 1.3 & 1.4 \\
\hline \multirow[t]{2}{*}{$\mathbf{P}, \mathbf{m m}$} & 106.6 & 83.2 & 59.4 & 51.0 & 47.1 & 18.0 \\
\hline & Temmuz & Ăgustos & Eylül & Ekim & Kasım & Aralık \\
\hline $\mathrm{T}_{\max },{ }^{\circ} \mathrm{C}$ & 33.9 & 34.9 & 33.2 & 29.4 & 22.6 & 16.7 \\
\hline $\mathbf{T}_{\min },{ }^{\circ} \mathbf{C}$ & 24.3 & 24.6 & 21.2 & 16.8 & 11.1 & 7.2 \\
\hline $\mathbf{N}$, saat & 10.2 & 9.8 & 8.8 & 7.4 & 5.8 & 4.3 \\
\hline RH, \% & 69.9 & 69.9 & 64.7 & 60.6 & 63.3 & 66.9 \\
\hline $\mathbf{U}, \mathbf{m} \mathbf{s}^{-1}$ & 1.5 & 1.3 & 1.2 & 1.1 & 1.1 & 1.3 \\
\hline $\mathbf{P}, \mathbf{m m}$ & 8.1 & 5.8 & 22.2 & 38.3 & 74.6 & 139.2 \\
\hline
\end{tabular}

$\mathrm{T}_{\max }$ : ortalama en yüksek sıcaklık; $\mathrm{T}_{\min }$ :ortalama en düşük sıcaklık; N: ortalama güneşlenme süresi; RH: ortalama oransal nem; U: ortalama rüzgar hızı $(10 \mathrm{~m})$; P: ortalama toplam yağış miktarı. 


\subsection{Modeller ve yaklaşımlar}

Çalışmada, 10 buharlaşma modeli, günlük olarak ölçülen A sınıfı kap buharlaşmasını tahmin etmek amacıyla; 30 yıllık günlük iklim verisi kullanılarak yöredeki bitki büyüme mevsimi (Nisan-Ekim) boyunca test edilmiştir. Kap buharlaşma değerleri, Meteoroloji 6. Bölge Müdürlüğü iklim istasyonundan sağlanmıştır.

\subsubsection{Kombinasyona dayalı buharlaşma modelleri}

\subsubsection{Penman modeli (1948)}

Jensen ve ark. (1990) tarafından, Penman (1948) lineer eşitliğinin kap buharlaşmasını ( $\left.E_{p a n}\right)$ tahmin etmek için verilen yeni formu aşağıdaki gibidir (Eşitlik 1). Eşitlik 1'deki havanın su buharı basıncı açığı (e $\mathrm{e}_{\mathrm{s}} \mathrm{e}_{\mathrm{a}}$ ) Eşitlik 2, 3 ve 4 kullanılarak belirlenmiştir.

$$
\begin{aligned}
& E=\frac{6.43 \times\left(1+0.53 \times U_{2}\right) \times\left(e_{s}-e_{a}\right)}{\lambda} \\
& e^{o} T=0.6108 \times \exp \left[\frac{17.27 \times T}{T+237.3}\right] \\
& e_{s}=\frac{e^{o}\left(T_{\max }\right)+e^{o}\left(T_{\min }\right)}{2} \\
& e_{a}=\frac{e^{o}\left(T_{\text {min }}\right) \times \frac{R H_{\text {max }}}{100}+e^{o}\left(T_{\text {max }}\right) \times \frac{R H_{\text {min }}}{100}}{2}
\end{aligned}
$$

Meteoroloji istasyonlarında rüzgar hızı 10 m yükseklikte ölçüldüğünden; bu değerler Kanber (2006) tarafından önerilen Eşitlik 5 kullanılarak 2 m’de yükseklikteki rüzgar hızı değerlerine dönüştürülmüştür.

$$
U_{2}=U_{10} x\left(\frac{Z_{2}}{Z_{10}}\right)^{0.15}
$$

Eşitliklerde; $\mathrm{E}=$ günlük buharlaşma miktarı $\left(\mathrm{mm} \mathrm{gün}^{-1}\right) ; \mathrm{U}_{2}=2 \mathrm{~m}$ yükseklikteki rüzgar hızı $\left(\mathrm{m} \mathrm{s}^{-1}\right) ; \mathrm{U}_{10}=10 \mathrm{~m}$ yükseklikteki rüzgar hızı $\left(\mathrm{m} \mathrm{s}^{-1}\right) ; \mathrm{Z}_{2}=2 \mathrm{~m} ; \mathrm{Z}_{10}=10 \mathrm{~m}$; $\mathrm{e}_{\mathrm{s}}=$ doygun buhar basıncı (mbar); $\mathrm{e}_{\mathrm{a}}=$ gerçek buhar basıncı (mbar); $\lambda=$ suyun buharlaşma gizli ısısı $\left(2.45 \mathrm{MJ} \mathrm{kg}^{-1}\right) ; \mathrm{T}=$ ortalama hava sıcaklığ $\left({ }^{\circ} \mathrm{C}\right)$; $\mathrm{T}_{\max }=$ en yüksek hava sıcaklığı $\left({ }^{\circ} \mathrm{C}\right) ; \mathrm{T}_{\min }=$ en düşük hava sıcaklığı $\left({ }^{\circ} \mathrm{C}\right) ; \mathrm{RH}_{\max }=$ en yüksek oransal nem $(\%) ; \mathrm{RH}_{\min }=$ en düşük oransal nem $(\%)$.

\subsubsection{Kohler-Nordenson-Fox (KNF) modeli (1955)}

Kohler ve ark. (1955) ABD’de Hefner gölünde kapsamlı araştırmalar yaparak, ABD geneline iyi dağılmış 21 adet A sınıfı buharlaşma kabının olduğu iklim istasyonlarından aldıkları verilerle yaptıkları hesaplamalarla, psikometrik sabiti ayarlayarak Penman (1948) buharlaşma denklemine uyarlamış ve aşağıdaki eşitlikleri geliştirmişlerdir (Eşitlik 6, 7, 8). Aşağıda verilen $\Delta, \gamma$ ve P eşitlikleri Anonim (2019)'dan; $U_{p}$ eşitlikliği ise Kanber (2006)'dan alınmıştır (Eşitlik $9,10,11,12)$.

$$
\begin{aligned}
& E=\frac{\Delta \times R_{n}+\gamma \times E_{a}}{\Delta+\gamma} \\
& E_{a}=25.4 \times\left[0.296 \times\left(e_{s}-e_{a}\right)^{0.88} \times\left(0.37+0.00255 \times U_{p}\right)\right] \\
& R_{n} \times \Delta=154.4 \times \exp \left[\begin{array}{c}
\left.(1.8 \times T-180) \times\left(0.1024-0.01066 \times \ln \left(0.239 \times R_{s}\right)\right)\right] \\
-0.01544
\end{array}\right. \\
& \Delta=\frac{4098 \times\left[0.6108 \times \exp \left(\frac{17.27 \times T}{T+237.3}\right)\right]}{(T+237.3)^{2}} \\
& \gamma=0.665 \times 10^{-3} \times \mathrm{P} \\
& \mathrm{P}=101.3 \times\left(\frac{293-0.0065 \times H}{293}\right) \\
& U_{p}=U_{10} \times\left(\frac{Z_{p}}{Z_{10}}\right)^{0.15}
\end{aligned}
$$

Eşitliklerde; $\mathrm{E}=$ günlük buharlaşma miktarı $\left(\mathrm{mm} \mathrm{gün}^{-1}\right) \Delta=$ doygun buhar basıncı eğrisinin eğimi $\left(\mathrm{kpa}^{\circ} \mathrm{C}^{-1}\right) ; \mathrm{R}_{\mathrm{n}}=$ 
Koç
Çukurova Yöresi Koşullarında Bazı Buharlaşma Modellerinin Performanslarının Değerlendirilmesi net radyasyon $\left(\mathrm{mm} \mathrm{gün}^{-1}\right) ; \mathrm{R}_{\mathrm{s}}=$ solar radyasyon $\left(\mathrm{J} \mathrm{cm}^{-2}\right.$ gün$\left.^{-1}\right) ; \mathrm{T}=$ ortalama hava sıcaklığ $\left({ }^{\circ} \mathrm{C}\right) ; \gamma=$ psikometrik sabit $=0.067176\left(\mathrm{kpa}^{\circ} \mathrm{C}^{-1}\right) ; \mathrm{P}=$ atmosfer basınc1 $=101.0166(\mathrm{kpa}) ; \mathrm{H}=$ konumun deniz seviyesinden yüksekliği $=24(\mathrm{~m})$; $\mathrm{E}_{\mathrm{a}}=$ aerodinamik fonksiyon (mm gün $\left.{ }^{-1}\right) ; \mathrm{U}_{10}=10 \mathrm{~m}$ yükseklikteki rüzgar hızı $\left(\mathrm{m} \mathrm{s}^{-1}\right) ; \mathrm{U}_{\mathrm{p}}=\mathrm{A}$ sınıfı buharlaşma kabının $15.2 \mathrm{~cm}$ üzerindeki rüzgâr hızı $=\left(\mathrm{m} \mathrm{s}^{-1}\right) \times 86.4=\left(\mathrm{km}_{\text {gün}}{ }^{-1}\right) ; \mathrm{Z}_{\mathrm{p}}=\mathrm{A}$ sınıfı buharlaşma kabının $15.2 \mathrm{~cm}$ üzerinde rüzgâr hareketinin olduğu yükseklik ile toprak yüzeyi arasındaki düşey uzaklık=0.6 m; $Z_{10}=10 \mathrm{~m}$.

\subsubsection{Kütle transferine dayalt buharlaşma modelleri}

\subsubsection{Papadakis modeli (1961)}

Basnyat (1987)' nin bildirdiğine göre; Papadakis (1961), buharlaşma miktarını belirlemek için, hava ve çiğlenme noktası sıcaklıklarındaki doygun buhar basınçları arasındaki farkı kullanan bir eşitlik (Eşitlik 13) geliştirmiştir.

$$
E=0.5626 \times\left(e_{s}-e_{d}\right)
$$

Eşitlikte; $\mathrm{E}=$ günlük buharlaşma miktarı $\left(\mathrm{mm} \mathrm{gün}^{-1}\right)$; $\mathrm{e}_{\mathrm{s}}=$ hava sıcaklığındaki doygun buhar basıncı (mbar); $\mathrm{e}_{\mathrm{d}}$ $=$ çiğlenme noktası sıcaklığındaki doygun buhar basıncı (mbar).

\subsubsection{Antal modeli (1973)}

Basnyat (1987)' nin bildirdiğine göre; Antal (1973), ortalama hava sıcaklığı ve havanın su buharı basıncı açığından $\left(e_{s}-e_{a}\right)$ faydalanarak buharlaşmayı kestirmek için basitleştirilmiş bir model (Eşitlik 14) geliştirmiştir.

$$
E=0.736 \times\left(e_{s}-e_{a}\right)^{0.7} \times\left(1+\frac{T}{273}\right)^{4.8}
$$

Eşitlikte; E = günlük buharlaşma miktarı $\left(\mathrm{mm} \mathrm{gün}^{-1}\right)$; $\mathrm{e}_{\mathrm{s}}=$ doygun buhar basıncı (mbar); e $\mathrm{e}_{\mathrm{a}}=$ gerçek buhar basıncı (mbar); $\mathrm{T}=$ ortalama hava sıcaklığ $\left({ }^{\circ} \mathrm{C}\right)$.

\subsubsection{Sicaklığa dayalı buharlaşma modelleri}

\subsubsection{Hamon modeli (1961)}

Hamon (1961), ortalama hava sıcaklığı ve güneşlenme süresine dayalı bir buharlaşma modeli geliştirmiştir (Eşitlik 15).

$$
\begin{aligned}
& E=0.55 \times D^{2} \times P_{t} \\
& P_{t}=\frac{4.95 \times e^{(0.062 \times T)}}{100}
\end{aligned}
$$

Eşitliklerde; $\mathrm{E}=$ günlük buharlaşma miktarı $\left(\mathrm{mm}_{\text {gün }}{ }^{-1}\right) ; \mathrm{D}=$ güneşlenme süresi (saat); $\mathrm{T}=$ ortalama hava sıcaklığ $\left({ }^{\circ} \mathrm{C}\right) ; \mathrm{Pt}=$ günlük ortalama sıcaklıktaki doygun su buharı yoğunluğu $\left(\mathrm{cg} \mathrm{m}^{-3}\right), \mathrm{cg}=$ santigram.

\subsubsection{Linacre modeli (1977)}

Linacre (1977), buharlaşma miktarını kestirmek için iklimsel veri girdilerini yalnızca hava sıcaklığına indirgeyerek, Penman (1948) eşitliğini basitleştirmiştir (Eşitlik 17). Tdew eşitliği Anonim (2019)'dan alınmıştır (Eşitlik 18).

$$
\begin{gathered}
\mathrm{E}=\frac{\frac{700 \times(\mathrm{T}+0.006 \times \mathrm{H})}{100-\mathrm{L}}+15 \times\left(\mathrm{T}-\mathrm{T}_{\mathrm{dew}}\right)}{(80-\mathrm{T})} \\
T_{\text {dew }}=\frac{116.91+237.3 \times \ln \left(e_{a}\right)}{16.78-\ln \left(e_{a}\right)}
\end{gathered}
$$

Eşitliklerde; $\mathrm{E}=$ günlük buharlaşma miktarı $\left(\mathrm{mm}\right.$ gün $\left.{ }^{-1}\right) ; \mathrm{T}=$ ortalama hava sıcaklığ $1\left({ }^{\circ} \mathrm{C}\right) ; \mathrm{T}_{\text {dew }}=$ ortalama çiğlenme noktası sıcaklığı; $\mathrm{L}=$ konumun enlem derecesi $=37\left(^{\circ}\right) ; \mathrm{H}=$ konumun deniz seviyesinden yüksekliği $=$ $24(\mathrm{~m}) ; \mathrm{e}_{\mathrm{a}}=$ gerçek buhar basıncı (mbar). 


\subsubsection{Kharrufa modeli (1985)}

Kharrufa (1985), açık su yüzeyi buharlaşmasını kestirmek için, güneşlenme yüzdesi ve ortalama hava sıcaklığına dayalı bir eşitlik geliştirmiştir (Eşitlik 19).

$$
E=0.34 \times \rho \times T^{1.3}
$$

Eşitlikte; $\mathrm{E}=$ günlük buharlaşma miktarı $\left(\mathrm{mm}_{\text {gün}}{ }^{-1}\right) ; \mathrm{T}=$ ortalama hava sıcaklığı $\left({ }^{\circ} \mathrm{C}\right) ; \rho=$ güneşlenme yüzdesi $(\%)$

\subsubsection{Radyasyona dayalı buharlaşma modelleri}

\subsubsection{Hanson \& Rauzi modeli (1977)}

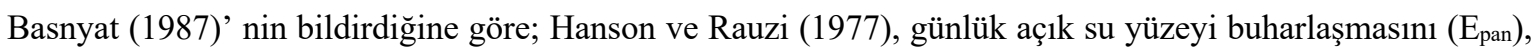
meteorolojik verilerden kestirmek için bir model (Eşitlik 20) geliştirmiştir.

$$
\begin{aligned}
E & =R \times(-0.06+0.036 \times T)+0.016 \times U_{2} \\
R & =0.77 \times R s
\end{aligned}
$$

Eşitlikte; $\mathrm{R}=$ kısa dalga radyasyonu $\left(\mathrm{mm}\right.$ gün $\left.{ }^{-1}\right) ; \mathrm{T}=$ ortalama hava sıcaklığ $1\left({ }^{\circ} \mathrm{C}\right) ; \mathrm{U}_{2}=2 \mathrm{~m}$ yükseklikteki rüzgar hızı $\left(\mathrm{m} \mathrm{s}^{-1}\right) ; \mathrm{R}_{\mathrm{s}}=$ solar radyasyon $\left(\mathrm{mm} \mathrm{gün}^{-1}\right)$

\subsubsection{Abtew modeli (1996)}

Abtew (1996), sulak alanlardan ve sığ su yüzeylerinden meydana gelen buharlaşmayı tahmin etmek için basit Abtew modelini geliştirmiştir (Eşitlik 22).

$$
E=K_{1} \times \frac{R_{S}}{\lambda}
$$

Eşitlikte; $\mathrm{E}=$ günlük buharlaşma miktarı $\left(\mathrm{mm}_{\mathrm{gün}}{ }^{-1}\right) ; \mathrm{K}_{1}=$ yüzey özelliğine bağlı bir katsayı $(0.53$, açık su yüzeyleri için); $\mathrm{R}_{\mathrm{s}}=$ solar radyasyon $\left(\mathrm{MJ} \mathrm{m}^{-2}\right.$ gün$\left.^{-1}\right) ; \lambda=$ suyun buharlaşma gizli isısı $\left(2.45 \mathrm{MJ} \mathrm{kg}^{-1}\right)$.

\subsubsection{Modified Turc modeli (Abtew, 1996)}

Turc (1961), oransal nemin \%50'den küçük ve büyük olduğu durumlara göre ortalama sıcaklık ve solar radyasyonu kullanan iki farklı eşitlik geliştirmiştir. Abtew (1996) Turc modelini değiştirerek maksimum sicaklık ve solar radyasyona dayanan oransal nemi dikkate almayan aşağıdaki eşitliği (Eşitlik 23) geliştirmiştir.

$$
E=\frac{\left.K_{2} \times\left(23.89 \times R_{S}+50\right) \times T_{\max }\right)}{\left(T_{\max }+15\right)}
$$

Eşitlikte; $\mathrm{E}=$ günlük buharlaşma miktarı $\left(\mathrm{mm} \mathrm{gün}^{-1}\right) ; \mathrm{K}_{2}=0.0123\left(\right.$ katsayı); $\mathrm{R}_{\mathrm{s}}=$ solar radyasyon $\left(\mathrm{MJ} \mathrm{m}^{-2}\right.$ gün $\left.{ }^{-1}\right) ; T_{\max }=$ en yüksek hava sıcaklığ $\left({ }^{\circ} \mathrm{C}\right)$.

\section{3. İstatistiksel analiz}

Buharlaşma modellerinin doğruluğunun ve güvenirliliğinin belirlenmesinde ortalama karekök hatası (RMSE), ortalama sapma hatası (MBE) ve bağıl hata (RE) istatistiksel yaklaşımları (Eşitlik 24-26) kullanılmıştır (Willmott, 1982; Loague ve Green, 1991).

$$
\begin{aligned}
& R M S E=\sqrt{\frac{1}{n} \sum_{i=1}^{n}\left(e_{i}-o_{i}\right)^{2}} \\
& M B E=\frac{\sum_{i=1}^{n}\left(e_{i}-o_{i}\right)}{n} \\
& R E=\frac{R M S E}{\bar{o}}
\end{aligned}
$$


Çukurova Yöresi Koşullarında Bazı Buharlaşma Modellerinin Performanslarının Değerlendirilmesi

Eşitliklerde; $\mathrm{n}=$ gözlem sayısı; $\mathrm{e}_{\mathrm{i}}=$ tahmin edilen kap buharlaşma değerleri $(\mathrm{mm}) ; \mathrm{o}_{\mathrm{i}}=$ ölçülen kap buharlaşma değerleri (mm); $\bar{o}=$ ölçülen kap buharlaşma değerlerinin ortalaması (mm). RMSE (mm.gün$\left.{ }^{-1}\right)$, RE ve MBE $\left(\mathrm{mm} \cdot\right.$ gün $\left.^{-1}\right)$ değerleri 0’a eşit olduğunda en doğru sonuç elde edilir.

\section{Araştırma Sonuçları ve Tartışma}

Araştırmada, bazı tahmin modelleri ile kestirilen ve buharlaşma kabından ölçülen açık su yüzeyi buharlaşması değerleri Tablo 2'de verilmiştir. Buna göre, Abtew (Nisan ayı hariç) ve Modified-Turc modelleri tüm aylarda buharlaşma değerlerini daha düşük tahmin ederken, Hamon, Papadakis, Antal, Linacre, Kharrufa ve Hanson-Rauzi modelleri tüm aylarda buharlaşma değerlerini daha yüksek tahmin etmiştir. Penman ve KNF yöntemi ise buharlaşma değerlerini bazı aylarda yüksek, bazı aylarda daha düşük kestirmiştir. Penman modeli, ölçülen kap buharlaşması değerlerine göre; nisan, mayıs, eylül ve ekim aylarında buharlaşma değerlerini daha yüksek, diğer aylarda daha düşük tahmin ederken; KNF modeli ise nisan, mayıs aylarında daha yüksek, diğer aylarda daha düşük tahmin etmiştir. Modellerin aylara göre buharlaşma değerini yüksek ya da düşük tahmin ettiği, Irmak ve Haman (2003) tarafindan da rapor edilmiştir. Modellere göre buharlaşma tahminleri aylık ortalama $2.9 \mathrm{~mm}_{\text {gün}}{ }^{-1}$ ile 17.5 mm gün ${ }^{-1}$ arasında değişmiştir. Ölçülen A sınıfı buharlaşma kabı ( $\left.E_{\text {pan }}\right)$ değerleri ise; en düşük ortalama $3.9 \mathrm{~mm}$ gün ${ }^{-1}$ ile nisan ayında; en yüksek ise ortalama 7.7 mm gün ${ }^{-1}$ ile temmuz ayında gerçekleşmiştir.

Tablo 2. Modeller ile tahmin edilen ve A sınıfi buharlaşma kabıyla ölçülen aylık ortalama buharlaşma değerleri ( $\left.E_{\text {pan }}\right)$, mm gün-1 (1990-2019)

Table 2. Mean monthly values of evaporation $\left(E_{p a n}\right)$ estimated using models and measured by Class A Pan, mm day $^{-1}$ (1990-2019)

\begin{tabular}{|c|c|c|c|c|c|c|c|c|c|c|c|}
\hline \multicolumn{12}{|c|}{ Model } \\
\hline Ay & $\mathbf{P}$ & KNF & PP & HM & $\mathbf{A N}$ & $\mathbf{L}$ & HR & $\mathbf{K}$ & $\mathbf{A}$ & MT & $\mathbf{E}_{\text {pan }}$ \\
\hline Nisan & 4.3 & 4.6 & 5.9 & 5.3 & 5.1 & 5.2 & 4.8 & 4.3 & 3.9 & 3.7 & 3.9 \\
\hline Mayıs & 5.4 & 5.9 & 7.5 & 9.8 & 6.5 & 6.5 & 6.3 & 7.1 & 4.6 & 4.5 & 5.3 \\
\hline Haziran & 6.3 & 7.0 & 8.5 & 15.3 & 7.5 & 7.6 & 8.0 & 10.0 & 5.0 & 5.1 & 7.1 \\
\hline Temmuz & 6.6 & 7.1 & 8.7 & 17.5 & 8.0 & 8.2 & 8.6 & 11.3 & 5.0 & 5.1 & 7.7 \\
\hline A ğustos & 7.0 & 6.5 & 9.6 & 16.8 & 8.7 & 8.6 & 7.8 & 11.2 & 4.4 & 4.7 & 7.2 \\
\hline Eylül & 7.1 & 5.4 & 10.1 & 11.7 & 8.6 & 8.2 & 6.3 & 8.9 & 3.8 & 4.0 & 5.8 \\
\hline Ekim & 6.1 & 3.9 & 9.0 & 6.7 & 7.4 & 7.1 & 4.3 & 6.0 & 2.9 & 3.0 & 4.0 \\
\hline Ortalama & 6.1 & 5.8 & 8.5 & 11.9 & 7.4 & 7.4 & 6.6 & 8.4 & 4.2 & 4.3 & 5.9 \\
\hline
\end{tabular}

Not: P = Penman; KNF = Kohler-Nordenson-Fox; PP = Papadakis; HM = Hamon; AN = Antal; L = Linacre; HR = Hanson\&Rauzi; K = Kharrufa; A = Abtew; MT = Modified-Turc; PAN = A sınıfı Pan'da ölçülen buharlaşma

Modellerin, bağıl hata (RE) değerleri Tablo 3'te verilmiştir. Hamon modeli, RE değerlerinde aylık ortalama olarak nisan ayında 1.0 ile en düşük, temmuz ayında 1.5 ile en yüksek ve mevsimsel ortalamada 1.3 ile en kötü performansı gösterirken; KNF modeli, aylık ortalama olarak temmuz ve ağustos ayında 0.2 ile en düşük, nisan ayında 0.6 ile en yüksek ve mevsimsel ortalamada 0.4 RE değerleri ile en iyi performansı göstermiştir (Tablo 3). Bağıl hata (RE) değerlerine göre tüm modeller (Hamon modeli hariç) bitki büyüme mevsimindeki diğer aylara göre; daha çok yağış alınan ve bulut yüzdesinin fazla olduğu nisan ve mayıs ve ekim aylarında daha büyük hatalar vermiştir. Kombinasyona dayalı olan Penman ve KNF modellerinin RE değerleri yüzde olarak ifade edilirse; Penman modeli için aylık ortalama yüzde RE değerleri nisan ve mayıs aylarında \%50, ekim ayında \%80 iken; KNF modeli için bu değerler nisan ayında \%60, mayıs ayında $\% 50$ ve ekim ayında \%40 olmuştur. Penman yönteminin bu aylarda daha kötü performans göstermesi, modelin solar radyasyon ve bulutluluktaki değişimleri dikkate almamasından; KNF modelinin ise bulutluluk durumunu dikkate almamasından kaynaklanmış olduğu söylenebilir. Aylık ortalama yüzde RE değerleri, Hamon hariç diğer tüm modellerde de anılan aylarda daha yüksek hatalar vermiştir. Irmak ve Haman (2003)' da, Florida'da yaptıkları benzer bir çalışmada Penman ve KNF yöntemlerinin kurak geçen aylarda daha düşük yüzde hatalar (PE) verdiğini, yağışlı aylarda ise daha yüksek hatalar (PE) verdiğini rapor etmiştir. Farklı iklim parametrelerini kullanan diğer modellerin de yağışlı aylarda (Hamon modeli hariç) daha yüksek RE değerleri verdiği görülmüştür. Güneşlenme süresi ve sıcaklık parametrelerini kullanan Hamon modeli bulutlu aylarda, diğer aylara göre daha doğru tahminler yaparken [(RE = 1.0 (Nisan), RE $=1.1$ (Ekim) $]$; kurak aylarda daha başarısız tahminler yapmıştır [(RE = 1.5 (Temmuz)]. Nemli ve yarı nemli bölgelerde, açık su yüzeyi buharlaşmasını etkileyen etmenlerin; sıcaklık ve rüzgâr desenindeki değişkenliklerden 
daha çok, solar radyasyon ve bulutlulukla ilgili olduğu bilinmektedir (Irmak ve Haman, 2003). Her bir modelin farklı düzeyde bağıl hatalar vermesine anılan etmenlerin neden olduğu söylenebilir.

Tablo 3. Modeller ile tahmin edilen aylık ortalama ve mevsimsel ortalama buharlaşma için RE değerleri (1990-2019)

Table 3. RE values for monthly and seasonal mean evaporation estimated by models (1990-2019)

\begin{tabular}{llllllllllll}
\hline \multicolumn{10}{c}{} & \multicolumn{10}{c}{ Model } \\
\hline Ay & P & KNF & PP & HM & AN & L & HR & K & A & MT \\
\hline Nisan & 0.5 & 0.6 & 0.8 & 1.0 & 0.6 & 0.7 & 0.6 & 0.7 & 0.5 & 0.5 \\
Mayıs & 0.5 & 0.5 & 0.7 & 1.3 & 0.6 & 0.6 & 0.6 & 0.7 & 0.4 & 0.4 & 0.3 \\
Haziran & 0.3 & 0.3 & 0.4 & 1.4 & 0.3 & 0.3 & 0.3 & 0.6 & 0.3 & 0.3 \\
Temmuz & 0.3 & 0.2 & 0.3 & 1.5 & 0.3 & 0.2 & 0.3 & 0.6 & 0.4 & 0.3 & 0.3 \\
Ăgustos & 0.3 & 0.2 & 0.5 & 1.5 & 0.3 & 0.3 & 0.3 & 0.7 & 0.4 & 0.3 \\
Eylül & 0.5 & 0.3 & 0.9 & 1.2 & 0.6 & 0.6 & 0.3 & 0.7 & 0.4 & 0.3 \\
Ekim & 0.8 & 0.4 & 1.6 & 1.1 & 1.1 & 1.1 & 0.4 & 0.9 & 0.4 & 0.4 \\
Ortalama & 0.5 & 0.4 & 0.8 & 1.3 & 0.6 & 0.5 & 0.4 & 0.7 & 0.4 & 0.4 \\
\hline
\end{tabular}

Modeller tarafından tahmin edilen buharlaşma değerleri için RMSE, RE ve MBE değerleri Tablo (3, 4, 5)'de verilmiştir. Tablolar incelendiğinde, KNF en düşük mevsimsel değerler ile (RMSE $=1.5 \mathrm{~mm} \mathrm{gün}^{-1}, \mathrm{RE}=0.4 \mathrm{ve}$ $\mathrm{MBE}=-0.1 \mathrm{~mm}$ gün $^{-1}$ ) en başarılı tahmin yapan model olurken; Hanson\&Rauizi, KNF modeline yakın değerler vererek $\left(\mathrm{RMSE}=1.6 \mathrm{~mm}\right.$ gün $^{-1}, \mathrm{RE}=0.4$ ve $\mathrm{MBE}=0.7 \mathrm{~mm}$ gün $\left.^{-1}\right)$ başarılı bir performans göstermiştir. Hamon modeli ise en yüksek mevsimsel değerleri vererek $\left(\mathrm{RMSE}=6.9 \mathrm{~mm}\right.$ gün-1, $\mathrm{RE}=1.3$ ve $\left.\mathrm{MBE}=6 \mathrm{~mm} \mathrm{gün}^{-1}\right)$ buharlaşma değerlerini tahmin etmede en başarısız model olmuştur Modellerin doğruluk sıralaması KNF $>$ Hanson\&Rauzi $>$ Modified-Turc $>$ Abtew $>$ Linacre $>$ Penman $>$ Antal $>$ Kharrufa $>$ Papadakis $>$ Hamon şeklinde gerçekleşmiştir. KNF modeli, Irmak ve Haman (2003) tarafından nemli bir iklime sahip Florida' da 5 buharlaşma modeli ile yapılan çalışmada ve Sezer ve ark. (2017) tarafından nemli bir iklime sahip Samsun'da 2 buharlaşma modelinin kullanıldığı çalışmada da en başarılı tahmin yapan model olarak belirlenmiştir.

Tablo 4. Modeller ile tahmin edilen aylık ortalama ve mevsimsel ortalama buharlaşma için RMSE değerleri, mm gün-1 (1990-2019)

Table 4. RMSE values for monthly and seasonal mean evaporation estimated by models, mm day ${ }^{-1}$ (1990-2019)

\begin{tabular}{|c|c|c|c|c|c|c|c|c|c|c|}
\hline \multicolumn{11}{|c|}{ Model } \\
\hline Ay & $\mathbf{P}$ & KNF & PP & HM & $\mathbf{A N}$ & $\mathbf{L}$ & HR & $\mathbf{K}$ & $\mathbf{A}$ & MT \\
\hline Nisan & 1.6 & 1.6 & 2.5 & 3.3 & 1.8 & 1.7 & 1.5 & 2.0 & 1.4 & 1.3 \\
\hline Mayıs & 2.0 & 1.8 & 3.0 & 5.9 & 2.1 & 1.8 & 1.8 & 2.9 & 1.7 & 1.7 \\
\hline Haziran & 2.3 & 1.7 & 2.6 & 8.9 & 1.9 & 1.6 & 1.8 & 3.6 & 2.3 & 2.3 \\
\hline Temmuz & 2.3 & 1.6 & 2.3 & 10.3 & 1.7 & 1.5 & 1.8 & 4.0 & 2.8 & 2.7 \\
\hline Ăgustos & 2.2 & 1.6 & 3.0 & 10.0 & 2.1 & 1.9 & 1.8 & 4.3 & 2.9 & 2.6 \\
\hline Eylül & 2.3 & 1.4 & 4.4 & 6.3 & 3.0 & 2.6 & 1.5 & 3.5 & 2.2 & 2.0 \\
\hline Ekim & 2.5 & 1.2 & 5.1 & 3.6 & 3.5 & 3.2 & 1.3 & 2.6 & 1.5 & 1.4 \\
\hline Ortalama & 2.2 & 1.5 & 3.2 & 6.9 & 2.3 & 2.0 & 1.6 & 3.3 & 2.1 & 2.0 \\
\hline
\end{tabular}

Modellerin, mevsimsel ortalama MBE değerleri, ölçülen buharlaşma değerlerine göre daha yüksek ya da daha düşük sonuçlar üretmiştir (Şekil 1). KNF (nisan ve mayıs ayları hariç), Abtew ve Modified-Turc eşitliklerinin MBE değerleri tüm aylarda ölçülen buharlaşma değerlerine göre daha düşük (negatif) değerler vermiştir. Penman, Papadakis, Hamon, Antal, Linacre, Kharrufa ve Hanson \& Rauzi modellerinin MBE değerleri ise tüm aylarda ölçülen buharlaşma değerlerine göre daha yüksek (pozitif) sonuçlar vermiştir. MBE değerlerine göre, KNF modeli mevsimsel ortalama buharlaşma değerleri için $\mathrm{MBE}=-0.1 \mathrm{~mm}$ gün ${ }^{-1}$ değeri ile en iyi sonucu verirken, Hamon tahmin modeli mevsimsel ortalama buharlaşma değerleri için $\mathrm{MBE}=6 \mathrm{~mm}$ gün ${ }^{-1}$ değeri ile en kötü performans gösteren model olmuştur. Papadakis $\left(\mathrm{MBE}=2.6 \mathrm{~mm}_{\text {gün}}{ }^{-1}\right)$ ve Kharrufa $\left(\mathrm{MBE}=2.5 \mathrm{~mm}\right.$ gün $\left.{ }^{-1}\right)$ modelleri de kötü performans göstermişlerdir (Tablo 5). 


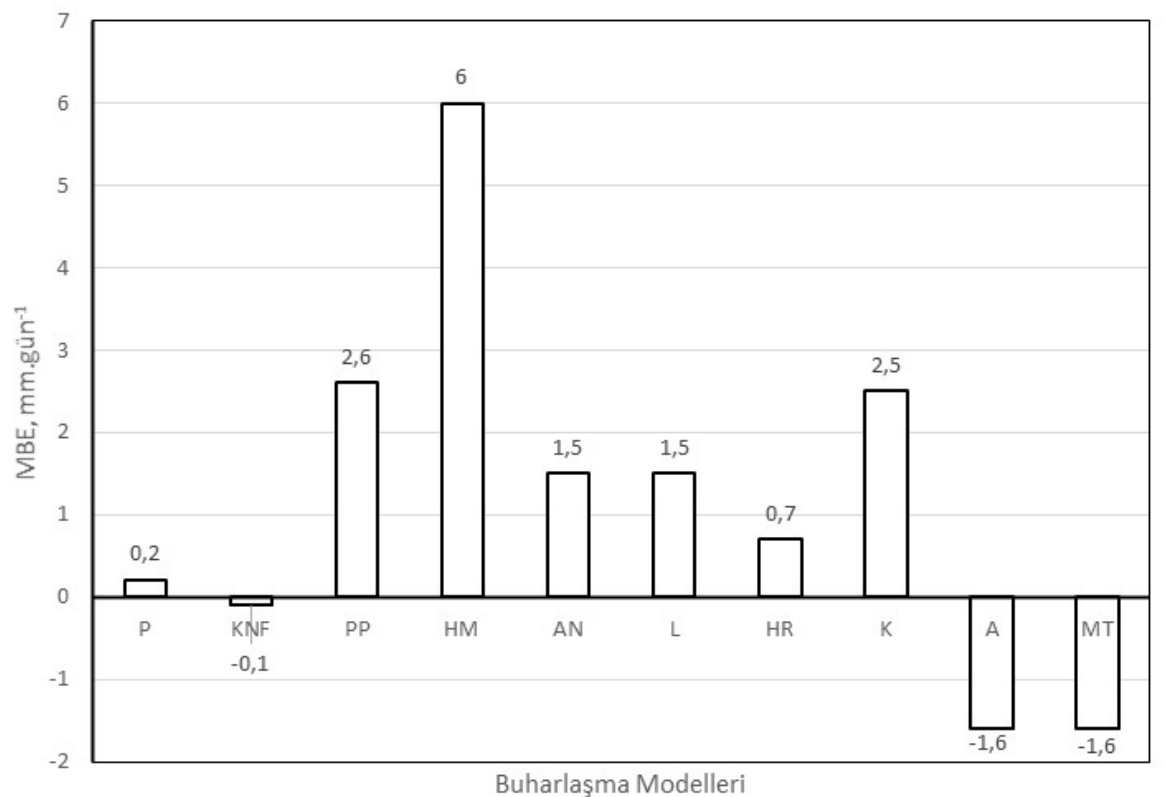

Figure 1. MBE values for mean seasonal evaporation estimated by models, mm day-1 (1990-2019)

Şekil 1. Modeller ile tahmin edilen mevsimsel ortalama buharlaşma için MBE değerleri, mm gün-1 (19902019)

Tablo 5. Modeller ile tahmin edilen aylık ortalama ve mevsimsel ortalama buharlaşma için MBE değerleri, mm gün ${ }^{-1}(1990-2019)$

Table 5. MBE values for monthly and seasonal mean evaporation estimated by models, mm day ${ }^{-1}$ (1990-2019)

\begin{tabular}{|c|c|c|c|c|c|c|c|c|c|c|}
\hline \multicolumn{11}{|c|}{ Model } \\
\hline Ay & $\mathbf{P}$ & KNF & PP & HМ & $\mathbf{A N}$ & $\mathbf{L}$ & HR & $\mathbf{K}$ & $\mathbf{A}$ & MT \\
\hline Nisan & 0.4 & 0.6 & 2.0 & 1.4 & 1.2 & 1.3 & 0.9 & 0.4 & 0.01 & -0.2 \\
\hline Mayıs & 0.1 & 0.6 & 2.2 & 4.5 & 1.2 & 1.2 & 1.0 & 1.8 & -0.7 & -0.8 \\
\hline Haziran & -0.8 & -0.1 & 1.4 & 8.2 & 0.4 & 0.5 & 0.9 & 2.9 & -2.1 & -2.0 \\
\hline Temmuz & -1.1 & -0.5 & 1.0 & 9.9 & 0.3 & 0.6 & 0.9 & 3.6 & -2.7 & -2.6 \\
\hline A ğustos & -0.3 & -0.8 & 2.4 & 9.6 & 1.4 & 1.4 & 0.5 & 4.0 & -2.8 & -2.6 \\
\hline Eylül & 1.2 & -0.4 & 4.3 & 5.8 & 2.8 & 2.4 & 0.5 & 3.1 & -2.0 & -1.8 \\
\hline Ekim & 2.1 & -0.1 & 5.0 & 2.7 & 3.4 & 3.1 & 0.3 & 2.0 & -1.1 & -1.0 \\
\hline Ortalama & 0.2 & -0.1 & 2.6 & 6.0 & 1.5 & 1.5 & 0.7 & 2.5 & -1.6 & -1.6 \\
\hline
\end{tabular}

\section{Sonuç}

Araştırmadan elde edilen sonuçlara göre; kombinasyon yöntemlerinden biri olan KNF, A sınıfı buharlaşma kaplarında ölçülen buharlaşmayı tahmin etmede en başarılı model olurken, radyasyona dayalı bir model olan Hanson\&Rauzi, KNF modeline oldukça yakın bir sonuç vermiştir. Her iki model de özellikle kurak geçen aylarda diğerlerine oranla daha doğru tahminler yapmışlardır. Sonuç olarak, KNF modeli, Çukurova iklim koşulları için A sınıfı buharlaşma kaplarından olan buharlaşmayı tahmin etmek için önerilebilir. Eğer iklim istasyonunda KNF modelini kullanmak için gerekli olan iklim öğeleri ölçülemiyorsa, daha az iklim parametresi gerektiren Hanson \& Rauzi modelinin yöre koşullarında aynı amaçla kullanılması önerilebilir. 


\section{Kaynakça}

Abtew, W. (1996). Evapotranspiration measurements and modeling for three wetland systems in South Florida. Journal of the American Water Resources Association 32 (3): 465-473.

Abtew, W. (2001). Evaporation estimation for Lake Okeechobee in south Florida. Journal of Irrigation and Drainage Engineering 127(3):140-147.

Anonim (2019). Food and Agriculture Organization of the United Nations (FAO), http://www.fao.org/3/x0490e/x0490e00.htm, (Erişim tarihi: 15.05.2019).

Anonim (2020). Meteoroloji Genel Müdürlüğü MGM), https://mevbis.mgm.gov.tr/mevbis/ui/index.html\#/Workspace, (Erişim tarihi: 12.02.2020).

Aydın, Y. (2019). Yarı kurak iklim koşullarında A Sınıfı Kap’tan olan buharlaşmanın Penman ve Kohler-Nordenson-Fox (KNF) modelleri ile tahmini. Türkiye Tarımsal Araştırmalar Dergisi 6 (3): 319-327.

Basnyat, M.B. (1987). Estimation of daily Class A pan evaporation from meteorological data (Dissertation of Doctor of Philosophy) Department of Agronomy, Iowa State University.

Ertek, A., Şensoy, S., Gedik, I., Küçükyumuk, C. (2007). Irrigation scheduling for green pepper grown in field conditions by using Class A pan evaporation values. American-Eurasian Journal of Agricultural \& Environmental Sciences 1818 (6769): 2-1.

Finch, J.W., Hall, R.L. (2001) Estimation of open water evaporation. R\&D Project W6- 043, Environment Agency. pp. 145.

Friedrich, K., Grossman, R.L., Huntington, J.L. et al. (2018). Reservoir evaporation in the Western United States: Current science, challenges, and future needs Bulletin of the American Meteorological Society 99 (1): 167-187.

Göçmen, E., Erdem, T. (2019). Tekirdağ Koşullarında Farklı Lateral Tertip Biçimi ve Sulama Suyu Uygulamalarının Genç Ceviz Ağaçlarının Su Kullanımı ve Vejetatif Gelişme Parametrelerine Etkileri. Tekirdağ Ziraat Fakültesi Dergisi 16 (2): 181-191

Hamon, W.R. (1961). Estimating potential evapotranspiration. Journal of Hydraulics Division 871: 107-120.

Irmak, S., Haman, D. (2003). Evaluation of five methods for estimating Class A Pan evaporation in a humid climate. Horttechnology 13 (3): $500-508$.

Jensen, M.E, Burman, R.D, Allen, R.G. (1990). Evapotranspiration and irrigation water requirements: a manual. ASCE manuals and reports on engineering practice, no. 70, Newyork.

Kanber, R. (2006). Sulama. Çukurova Üniversitesi Ziraat Fakültesi Genel Yayın No: 174, Adana.

Kharrufa, N.S. (1985). Simplified equation for evapotranspiration in arid regions. Beiträge zur Hydrologie Sonderheft 5 (1): 39-47.

Kohler, M.A., Nordenson, T.J., Fox, W.E. (1955) Evaporation from pans and lakes. U.S. Department of Commerce, Weather Bureau, Research Paper no. 38 .

Linacre, E.T. (1977). A simple formula for estimating evaporation rates in various climates, using temperature data alone. Journal of Agricultural Meteorology 18: 409-424.

Loague, K., Green, R.E. (1991). Statistical and graphical methods for evaluating solute transport models: overview and application. Journal of Contaminant Hydrology 7 (1-2): 51-73.

Rodrigues, C., Moreira, M., Guimarães, R.C., Potes, M. (2020). Reservoir evaporation in a Mediterranean climate: comparing direct methods in Alqueva Reservoir, Portugal. Hydrology and Earth System Sciences 24 (12): 5973-5984.

Rosenberry, D.O., Winter, T.C., Buso, D.C., Likens, G.E. (2007). Comparison of 15 evaporation methods applied to a small mountain lake in the northeastern USA. Journal of Hydrology 340 (3-4): 149-166.

Sezer, Ç.Ö., Öztekin, T. (2016). A Sınıfı buharlaşma kabından olan günlük buharlaşmanın Penman ve Linacre modelleri ile tahmini. Gaziosmanpaşa Üniversitesi Ziraat Fakültesi Dergisi 33 (3) :137-147.

Sezer, Ç.Ö., Öztekin, T., Kutlu Sezer, E. (2017). A Sınıfı buharlaşma kabından olan günlük buharlaşmanın Kohler-Nordenson-Fox (KNF) ve Christiansen Modelleri ile tahmini. Gaziosmanpaşa Bilimsel Araştırma Dergisi 6: 184-196.

Willmot, C.J. (1982). Some comments on the evaluation of model performance. Bulletin of the American Meteorological Society 63: $1309-1313$.

Winter, T.C., Rosenberry, D.O., Sturrock, A.M. (1995). Evaluation of 11 equations for determining evaporation for a small lake in the North Central United States. Water Resources Research 31:983-993.

Xu, C.Y., Singh, V.P. (2000). Evaluation and generalization of radiation-based methods for calculating evaporation. Hydrological Processes 14: 339349.

Xu, C.Y., Singh, V.P. (2001). Evaluation and generalization of temperature-based methods for calculating evaporation. Hydrological Processes 15: 305-319.

Yenigün, S.D., Erdem, T. (2019). Tekirdağ Koşullarında Patlıcan Bitkisinin Su Kullanım Özelliklerinin Belirlenmesi. Tekirdağ Ziraat Fakültesi Dergisi $16(2): 221-231$ 